\title{
Comparison of macular thickness in myopia, hypermetropia and emmetropia: An OCT based study
}

\author{
Tanu Raja ${ }^{1}$, Pragati Garg, ${ }^{2, *}$ Astha Agrawal ${ }^{3}$ \\ ${ }^{1}$ Research Fellow, Prakash Netra Kendra, Lucknow, Uttar Pradesh, ${ }^{2} \mathrm{HOD},{ }^{3} \mathrm{~J} u n i o r$ Resident III, Dept. of Ophthalmology, Era's \\ Lucknow Medical College, Lucknow, Uttar Pradesh, India \\ *Corresponding Author: \\ Email: drastha123@gmail.com
}

\begin{abstract}
Aim: To make a comparative evaluation of macular thickness in myopia and hypermetropia versus emmetropia.

Materials and Methods: A cross-sectional OCT based study was done in randomly selected 100 emmetropes, 93 myopes, 67 hypermetropes aged between 18 to 30 years regardless of sex.

Results: Average outer macular thickness in emmetropia, myopia and hypermetropia is $276.63 \pm 12.5,275.43 \pm 12.1,286.56 \pm 11.4$ respectively. Average inner macular thickness was $316.45 \pm 11.5,308.83 \pm 11.3,310.70 \pm 12.1$ respectively and average central subfield thickness was $243.80 \pm 11.2,248.51 \pm 22.9,240.05 \pm 21.9$ respectively.

Conclusion: Overall macular thickness in various quadrants was uniform in emmetropia. As compared to emmetropia in myopia average outer and inner subfield macular thickness is lower while average central thickness is higher. In hypermetropia average inner macular and central subfield thickness is lower while outer macular thickness is higher $(\mathrm{p}=0.001)$.
\end{abstract}

Keywords: Macular thickness, Myopia, Hypermetropia, Emmetropia.

\section{Introduction}

Uncorrected refractive errors account for half of the global burden of avoidable vision impairment and nearly a third of the global burden of avoidable blindness. ${ }^{1}$ An average of 153 million people approximately are estimated to be visually impaired from uncorrected refractive error of whom eight million are blind. ${ }^{2}$

Uncorrected refractive error has been as a priority public health condition by a joint programme of the World Health Organization and the International Agency for the Prevention of Blindness under the global initiative, vision 2020. ${ }^{3}$

Evidence from human as well as animal studies have shown that retinal changes play an important role in the pathogenesis of refractory errors. ${ }^{4-6}$ Retinal thickness using optical coherence tomography reportedly ranges from $101.07 \pm 10.13 \mu \mathrm{m}$ to $127.47 \pm 15.57 \mu \mathrm{m}$ in normal healthy Indian population. ${ }^{7}$ Within same individual a variation in retinal thickness has been reported in various quadrants with values in temporal quadrant being minimum (59.95 \pm 7.84 to $68.16 \pm 9.98 \mu \mathrm{m})$ and those in superior and inferior quadrants being higher (119.0 \pm 18.01 to $132.16 \pm 8.90 \mu \mathrm{m})$.

In the macular region, the thickness measured through OCT shows a high variability with values ranging from $190 \mu \mathrm{m}$ (center point) to $387 \mu \mathrm{m}$ (superior inner/nasal inner macula). ${ }^{8}$ For both retinal and macular regions, a declining trend in retinal thickness has been reported with increasing age.

The retinal macular thickness is dependent on a multitude of factors including age, gender, ethnicity, axial length and refraction. ${ }^{9-11}$ and as such it is difficult to ascertain any one variable as the reason for change in retinal macular thickness. It has been a common observation that two person with similar refractive status of eye; both in terms of type and extent of error may not have same extent BCVA. This may be thought of due to retinal changes in form of its thickness, specially in macular area.

Most of the studies are from East Asian countries and there is limited or no data available with respect to evaluation of relationship between refractive error status and retinal macular thickness from Indian subcontinent. As ethnicity is one of the factors effecting retinal macular thickness, it is of interest to explore possible relationship between retinal macular thickness with respect to refractive status of eye in Indian population. The foregoing background prompted to evaluate refractive status of eye and macular retinal thickness in a subset of North Indian population using OCT.

\section{Materials and Methods}

It was a cross-sectional study carried out on 260 individuals in a duration of 18 months in a tertiary hospital on subjects aged between 18-30 years attending the ophthalmology OPD.

Individuals having similar type of refractive status in both the eyes and with no known confounding factor affecting retinal integrity or BCVA were included in the study while the patients having ocular complications like posterior segment pathology, media opacity, history of glaucoma, history of laser therapy, history of trauma and those patients having systemic conditions like pregnancy, history of hypertension, diabetes mellitus or Renal disease were excluded from the study group.

All the subjects falling in the sampling frame were included in the study after their informed consent and institutional ethical clearance. In all patients Demographic and anthropometric details were noted. A detailed personal and medical history was obtained. All 
the subjects were subjected to thorough general, systemic and ocular examination which included visual acuity with and without pinhole by Snellen's chart, retinoscopy for assessment of BCVA by subjective spectacle correction, fundus examination by direct ophthalmoscopy and 90D lens, slit lamp examination and optical coherent tomography for assessing the macular thickness.

For this study we used a scan pattern composed of $200 \times 200$ A-scans, which covers uniformly a $6 \times 6 \mathrm{~mm}$ square on the retina. The depth of each scan is $2 \mathrm{~mm}$. Each subject had both eyes scanned during image acquision.

Macular thickness measurements were obtained in nine regions. The central circle has a diameter of $1 \mathrm{~mm}$. The inner circle has a diameter of $3 \mathrm{~mm}$ and is divided into 4 quadrants. Thickness values obtained from retinal segmentation were averaged to give the mean thickness in each quadrant. Laboratory investigations done were blood sugar, lipid profile, serum creatinine and blood urea to exclude the confounding factors.

Data was compiled and analysed using statistical package for social sciences version 15.0. Chi square test was used for comparison of categorical data. Analysis of variance and independent sample ' $t$ ' test were used to compare the parametric data among and between groups. Paired ' $t$ '- tests was used to compare the pair wise differences. Confidence level of the study was kept at $95 \%$ and $\mathrm{p}$ value of less than 0.05 is taken as statistically significant.

\section{Results}

Table 1: Gender distribution of studied patients

\begin{tabular}{|l|c|c|c|c|}
\hline \multirow{2}{*}{$\begin{array}{c}\text { Gender } \\
(\mathbf{N}=\mathbf{2 6 0})\end{array}$} & $\begin{array}{c}\text { Emmetropia } \\
(\mathbf{N = 1 0 0 )}\end{array}$ & $\begin{array}{c}\text { Myopia } \\
(\mathbf{N = 9 3})\end{array}$ & $\begin{array}{c}\text { Pypermetropic } \\
(\mathbf{N}=\mathbf{6 7})\end{array}$ & \\
\hline Female(159) & 60 & 60 & 39 & \\
\hline Male(101) & 40 & 33 & 28 & 0.690 \\
\hline
\end{tabular}

Table 2: Macular subfield thickness analysis in emmetropia, myopia and hypermetropia

\begin{tabular}{|c|c|c|c|c|c|}
\hline & $\begin{array}{c}\text { Emmetropia } \\
(\mathrm{N}=\mathbf{1 0 0})\end{array}$ & $\begin{array}{c}\text { myopia } \\
(\mathrm{N}=93)\end{array}$ & $\begin{array}{c}\text { Hypermetropia } \\
(\mathrm{N}=67)\end{array}$ & & \\
\hline Macular subfield & Thickness, $\mu \mathrm{m}$ & $\begin{array}{c}\text { Thickness, } \\
\mu \mathrm{m}\end{array}$ & Thickness, $\mu \mathrm{m}$ & \multirow[t]{2}{*}{$\begin{array}{c}\text { P value }(\mathbf{E} \\
\text { VS M) }\end{array}$} & \multirow[t]{2}{*}{$\begin{array}{l}\text { P value } \\
(\mathrm{E} \text { VS H) }\end{array}$} \\
\hline & $($ Mean \pm SD $)$ & $($ Mean \pm SD $)$ & $($ Mean \pm SD $)$ & & \\
\hline (A) Central subfield & $243.80 \pm 11.2$ & $248.51 \pm 22.9$ & $240.05 \pm 21.9$ & 0.068 & 0.15 \\
\hline $\begin{array}{l}\text { (B) Inner Macular } \\
\text { thickness (Average) }\end{array}$ & $316.45 \pm 11.5$ & $308.83 \pm 11.3$ & $310.70 \pm 12.1$ & 0.001 & 0.003 \\
\hline Superior quadrant & $331.44 \pm 19.8$ & $305.73 \pm 23.8$ & $310.12 \pm 18.2$ & & \\
\hline Inferior quadrant & $313.67 \pm 9.6$ & $301.92 \pm 25.8$ & $310.81 \pm 16.4$ & & \\
\hline Nasal quadrant & $314.59 \pm 7.2$ & $305.96 \pm 29.7$ & $314.58 \pm 16.1$ & & \\
\hline Temporal quadrant & $306.13 \pm 8.7$ & $291.90 \pm 21.2$ & $307.30 \pm 14.3$ & & \\
\hline $\begin{array}{l}\text { (C) Outer Macular } \\
\text { thickness (Average) }\end{array}$ & $276.63 \pm 12.5$ & $275.43 \pm 12.1$ & $286.56 \pm 11.4$ & 0.499 & $<0.001$ \\
\hline Superior quadrant & $279.24 \pm 9.3$ & $277.92 \pm 23.3$ & $288.00 \pm 18.1$ & & \\
\hline Inferior quadrant & $266.99 \pm 8.5$ & $266.73 \pm 23.6$ & $284.00 \pm 20.8$ & & \\
\hline Nasal quadrant & $295.50 \pm 9.0$ & $295.80 \pm 23.6$ & $301.73 \pm 20.3$ & & \\
\hline Temporal quadrant & $264.79 \pm 12.4$ & $261.28 \pm 24.7$ & $272.52 \pm 19.9$ & & \\
\hline $\begin{array}{l}\text { Overall Average Macular } \\
\text { Thickness }(p<0.001)\end{array}$ & $290.69 \pm 4.9$ & $284.34 \pm 14.7$ & $292.13 \pm 8.5$ & & \\
\hline
\end{tabular}

This cross sectional study was conducted on 260 patients of which 100 were emmeteropic 95 were myopic and 67 were hypermetropic. Internal M:F ratio was 3:5 with insignificant gender distribution $(\mathrm{p}=0.690)$ (Table 1)

Macular subfeild thickness analysis in the 3 groups showed that the central subfeild thickness was 243.80 +/- 11.2um in emmetropia, 248.51+/-22.9um in myopia and 240.05+/-21.9um in hypermetropia. Even though myopic patients have slightly higher central subfeild thickness but the difference is insignificant $(\mathrm{p}=0.068)$

The average outer macular thickness was 276.63+/-12.5um in emmetropia, 275.43+/-12.1um in myopia \& 286.56+/-11.4um in hypermetropia. These values were almost similar between emmetropia and myopia but the difference between emmetropia and hypermetropia was found to be statistically significant $(\mathrm{p}<0.001)$ 
Further the outer macular thickness was seen in various quadrants. The observation was that it was thickest in the nasal quadrant and thinnest in the temporal quadrant in all the groups.

The average inner macular thickness was 316.45+/-11.5um, 308.83+/-11.3um \& 310.70+/-12.1um respectively in emmetropia, myopia \& hypermetropia. The difference was significant both when myopia was compared with emmetropia $(\mathrm{p}=0.001) \quad \&$ when hypermetropia was compared with emmetropia $(\mathrm{p}=0.003)$. Further quadrantic division revealed that this inner macular thickness was maximum in superior quadrant in emmetropia \& myopia, and in nasal quadrant in hypermetropia while it was minimum in the temporal quadrants in all the groups.

In emmetropia the overall macular thickness in various quadrants remain uniform while individually in both myopia as well as in hypermetropia, average inner macular thickness was on a higher side compared to among the other macular subfeild (Table 2). The variation in overall average macular thickness between the three groups was highly significant $(\mathrm{p}<=0.001)$.

\section{Discussion}

The analysis of the macular subfield thickness in emmetropia showed that central subfield thickness was $243.80 \pm 11.2 \mu \mathrm{m}$, inner macular thickness was $316.45 \pm 11.5 \mu \mathrm{m}$ and the average outer macular thickness was $276.63 \pm 12.5 \mu \mathrm{m}$. In Inner macular and outer macular area the thickness variation in different quadrants was statistically non significant. However the overall average Inner Macular thickness is much higher compared to overall average thickness of the other macular subfield. In Study by Pradhan Z.S. et al, ${ }^{12}$ they studied the macular thickness in normal Indian eyes and they reported that on evaluating the macular thickness in the 9 ETDRS regions in our population, the nasal macula (inner and outer areas) was significantly thicker than the temporal macula, where as in the present study the thickness in the superior quadrant was more in inner macular area where as in outer macular area it was nasal quadrant which was thicker.

In myopia average central subfield thickness was $248.51 \pm 22.9 \mu \mathrm{m}$, inner macular thickness was $308.83 \pm 11.3 \mu \mathrm{m}$ and the outer macular thickness was $275.43 \pm 12.1 \mu \mathrm{m}$. The difference of thickness in different quadrants of inner macular and outer macular area was statistically non-significant. In the present study we found that the average inner macular thickness is on a much higher side compared to among the other macular subfield.

In hypermetropia central subfield thickness was $240.05 \pm 21.9 \mu \mathrm{m}$, inner macular thickness was $310.70 \pm 12.1 \mu \mathrm{m}$ and the outer macular thickness was $286.56 \pm 11.4 \mu \mathrm{m}$. The average inner macular thickness is on a much higher side in this analysis among all the other macular subfield, The difference of thickness in various quadrants of inner macular thickness and outer macular areas was statistically non significant. In the available literature there are no studies reported making comparison of thickness variation among the macular subfield in hypermetropia.

Comparative correlation between average macular thickness and refractive status i.e, emmetropia, myopia and hypermetropia (Table 2) showed that the average macular thickness in emmetropia was $290.69 \pm 4.9$, in myopia was $284.34 \pm 14.7$, and in hypermetropia was $292.13 \pm 8.5$ respectively. The difference of variation between the three groups was highly significant. There is no comparable study reported in screened literature in this regard.

Further comparative analysis of macular subfield thickness done between emmetropia and myopia groups, revealed that inner macular subfield thickness was found to be significantly lessen myopia compared to emmetropia while central and outer subfield thickness was comparable between two groups.

Likewise comparative analysis of macular subfield thickness done between emmetropia and hypermetropia groups, showed that inner macular subfield thickness is significantly less $(\mathrm{p}=0.003)$ in comparison to emmetropia and outer subfield thickness is significantly $(\mathrm{p}=<0.001)$ more.

\section{Conclusion}

OCT yields accurate retinal thickness measurements with greater reproducibility. In emmetropia the overall macular thickness in various quadrants remains uniform. The thickness variation in different quadrants is statistically non significant. Individually in both myopic as well as hypermetropic eyes average inner macular thickness is on a higher side compared to among the other macular subfield. The overall average macular thickness variations amongst the three groups i.e emmetropia, myopia and hypermetropia is highly significant, being least in myopia ( $\mathrm{p} \leq 0.001)$. In myopia the inner macular subfield thickness, compared to normal (Emmetropia), is less which is statistically significant $(p=0.001)$.In hypermetropic the outer subfield thickness compared to normal (Emmetropia) is more, which is statistically significant $(<0.001)$.

\section{References}

1. Cochrane GM, du Toit R, Le Mesurier TR. Management of refractive errors. BMJ. 2010;340:c1711.

2. Resnikoff S, Pascolini D, Mariotti S, Pokharel G. Global magnitude of visual impairment caused by uncorrected refractive errors in 2004. Bull World Health Organ. 2008,;86(1):63-70.

3. Gupta A, Lal R, Mazta SR, Sharma D. Prevalence of Refractive Errors, Color Vision Defects and Other Ocular Disorders in School-going Children: Primary Screening by School Teachers. JIMSA. 2012;25(4):223-24.

4. Diether S, Schaeffel F. Local changes in eye growth induced by imposed local refractive error despite active accommodation. Vision Res. 1997;37(6):659-68. 
5. Wolsley CJ, Saunders KJ, Silvestri G, Anderson RS. Investigation of changes in the myopic retina using multifocal electroretinograms, optical coherence tomography and peripheral resolution acuity. Vision Research. 2008;48:1554-1561.

6. Benavente-Pérez A, Nour A, Troilo D. Axial eye growth and refractive error development can be modified by exposing the peripheral retina to relative myopic or hyperopic defocus. Invest Ophthalmol Vis Sci. 2014;55(10):6765-73.

7. Malik A, Singh M, Arya SK, Sood S, Ichhpujani P. Retinal nerve fiber layer thickness in Indian eyes with optical coherence tomography. Nepal J Ophthalmol. 2012;4(7):59-63.

8. Appukuttan B, Giridhar A, Gopalakrishnan M, Sivaprasad S. Normative spectral domain optical coherence tomography data on macular and retinal nerve fiber layer thickness in Indians. Indian J Ophthalmol. 2014;62(3):316-21.

9. Tewari HK, Wagh VB, Sony P, Venkatesh P, Singh R. Macular thickness evaluation using the optical coherence tomography in normal Indian eyes. Indian J Ophthalmol. 2004;52(3):199-204.
10. Chan C-M, Yu J-H, Chen L-J, Huang C-H, Lee C-T, Lin T-C, Liu D-Z. Posterior pole retinal thickness measurements by the retinal thickness analyzer in healthy Chinese subjects. Retina. 2006; 26(2):176-181.

11. Zou H, Zhang X, Xu X, Yu S. Quantitative in vivo retinal thickness measurement in Chinese healthy subjects with retinal thickness analyzer. Invest Ophthalmol Vis Sci. 2006;47(1):341-347.

12. Pradhan ZS, Braganza A, Abraham LM. Determinants of macular thickness in normal Indian eyes. J Clin Ophthalmol Res. 2013;1(1):11-6.

How to cite this article: Raja T, Garg $\mathrm{P}$, Agrawal A. Comparison of macular thickness in myopia, hypermetropia and emmetropia: An OCT based study. Ind J Clin Exp Ophthalmol. 2018;4(3):329-332. 